\title{
Comparison of Beta-2 Adrenergic Receptor Gene Polymorphisms Between Patients With Fibromyalgia Syndrome and Healthy Controls
}

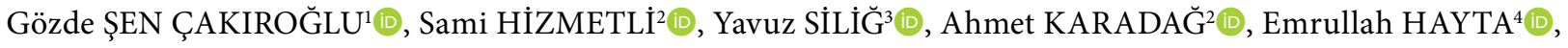 \\ Burcu ÖZALTIN ${ }^{5}$, Ayça TAŞ3⿻ ${ }^{3}$, Cemile ZONTUL ${ }^{3}$ \\ ${ }^{1}$ Department of Physical Medicine and Rehabilitation, Niğde State Hospital, Niğde, Turkey \\ ${ }^{2}$ Department of Physical Medicine and Rehabilitation, Cumhuriyet University Faculty of Medicine, Sivas, Turkey \\ ${ }^{3}$ Department of Biochemistry, Cumhuriyet University Faculty of Medicine, Sivas, Turkey \\ ${ }^{4}$ Department of Physical Medicine and Rehabilitation, Acıbadem Hospital, İstanbul, Turkey \\ ${ }^{5}$ Department of Physical Medicine and Rehabilitation, Anamur State Hospital, Mersin, Turkey
}

\begin{abstract}
Objectives: This study aims to compare the beta-2 adrenergic receptor (ADRB2) gene polymorphisms of patients with fibromyalgia syndrome (FMS) with those of healthy control subjects, and to investigate the possible relationship between symptoms of FMS and polymorphisms of the ADRB2 gene.

Patients and methods: The study included 170 females (mean age $47.8 \pm 10.3$ years; range, 21 to 75 years) diagnosed with FMS according to the 2010 American College of Rheumatology criteria and 170 healthy females (mean age $47.2 \pm 8.8$ years; range, 20 to 72 years) as the control group. Several clinical symptoms of the participants related to FMS were questioned and recorded. The visual analog scale (VAS) and Fibromyalgia Impact Questionnaire (FIQ) scores of the fibromyalgia group were recorded. In both groups, the ADRB2 (rs1042717) single-nucleotide polymorphism was detected by way of a real-time polymerase chain reaction. The wild-type (Guanine/Guanine), the mutant type (Adenine/Adenine) and heterozygous type (Adenine/Guanine) were detected. The sample power was calculated considering the minor allele frequency.

Results: The comparison of the ADRB2 gene polymorphism between patients with FMS and the control subjects showed that the groups were similar in terms of ADBR2 gene polymorphism and genotype ( $p>0.05$ ). There was no significant difference in terms of genotype when the ADRB2 gene polymorphisms in patients with FMS were compared in terms of clinical symptoms, VAS and FIQ scores ( $p>0.05)$.

Conclusion: Beta-2 adrenergic receptor ( $r$ 1042717) gene polymorphisms and genotype distribution are no different between patients with FMS and healthy individuals. ADRB2 gene polymorphisms in patients with FMS have no effect on clinical symptoms and VAS and FIQ scores. The results of the present study will light the way for future research into ADRB2 gene polymorphisms in the pathogenesis of FMS.

Keywords: Beta-2 adrenergic receptor, fibromyalgia syndrome, polymorphism.
\end{abstract}

Fibromyalgia syndrome (FMS) is a clinical condition characterized by widespread pain, fatigue, sleep disturbance and cognitive dysfunction. ${ }^{1}$ Genetic, environmental and immunological factors, as well as peripheral and central mechanisms, are considered to play a role in its etiopathogenesis. ${ }^{2,3}$ Previous clinical studies into the pathogenesis of FMS have identified disturbances in the sympathetic and parasympathetic systems and associated dysfunctions in the autonomic nervous system. These studies have also shown that a number

Received: May 09, 2019 Accepted: October 05, 2019 Published online: February 07, 2020

Correspondence: Ahmet Karadağ, MD. Cumhuriyet Üniversitesi Tıp Fakültesi Fiziksel Tıp ve Rehabilitasyon Anabilim Dalı, 58140 Sivas, Türkiye. Tel: +90 506 - 5335456 e-mail:dr_ahmetkaradag@hotmail.com Fibromyalgia Syndrome: A Cross-Sectional Study. Arch Rheumatol 2020;35(3):328-334. 
of clinical findings in FMS could be associated with autonomic dysfunction. ${ }^{4-7}$ That said, various other studies have provided evidence that gene polymorphisms in serotoninergic and catecholaminergic systems, along with strong familial predisposition, could play a role in the etiopathogenesis of FMS. ${ }^{8-10}$

\section{Catecholamines are sympathetic} neurotransmitters that exert their effects by binding to adrenergic receptors (ARs). CatecholO-methyltransferase (COMT) is the main enzyme involved in the breakdown of catecholamines, and it has been reported previously that COMT plays a role in pain modulation. ${ }^{5}$ Another study has shown that the polymorphism of the gene that encodes the COMT enzyme may also be involved in the pathogenesis of FMS. ${ }^{11-13}$ The fact that catecholamines exert their effects by binding to ARs, and the demonstration of increased pain sensitivity through the activation of ARs due to low COMT activity in these studies have prompted further research into AR gene polymorphisms in various diseases.

Polymorphisms are defined as nucleotide changes that do not cause, but may predispose to a disease condition. ${ }^{14}$ Polymorphic changes can occur in various ways, with single-nucleotide polymorphisms (SNPs) being the most common. ${ }^{15}$ AR gene polymorphisms substantially affect the sensitivity and functions of ARs. AR polymorphisms have been shown to be associated with various disorders, such as cardiovascular diseases, asthma, obesity and chronic pain. ${ }^{16-18}$

Dysfunctional ARs have been implicated in the pathogenesis of chronic painful conditions. ${ }^{19}$ Adrenergic receptors are divided into two main groups, as alpha and beta. Beta-adrenergic receptors (ADRBs) are important components of the sympathetic nervous system. ${ }^{20}$ The haplotypes made up of the gene variants of beta- 2 adrenergic receptors (ADRB2) have been shown to be associated with chronic pain by affecting receptor expression levels and ligand binding. ${ }^{21}$

The authors therefore hypothesized that the ADRB2 gene polymorphisms that were shown to be associated with chronic pain may also be involved in the pathogenesis of FMS. There is a paucity of studies in the literature evaluating the relationship between FMS and ADRB2 gene polymorphisms, ${ }^{22,23}$ and the relevant studies in the literature have yet to make a clear identification of the relationship between the two. To the best of our knowledge, ADRB2 gene polymorphisms (rs1042717 Adenine/Guanine [AG]) are yet to be studied in FMS. Therefore, in this study, we aimed to compare the ADRB2 gene polymorphisms (rs1042717G/A) of patients with FMS with those of healthy control subjects, and to investigate the possible relationship between symptoms of FMS and polymorphisms of the ADRB2 gene.

\section{PATIENTS AND METHODS}

The study was conducted at the Physical Medicine and Rehabilitation Clinic of Sivas Cumhuriyet University Medical Faculty between March 2017 and March 2018 and included 170 female patients (mean age $47.8 \pm 10.3$ years; range, 21 to 75 years) who were newly diagnosed with FMS according to the 2010 American College of Rheumatology ${ }^{24}$ criteria, and 170 female healthy control subjects (mean age $47.2 \pm 8.8$ years; range, 20 to 72 years). The entire study group was composed of female patients and control subjects so as to eliminate possible differences in genetic and clinical parameters caused by sex, and to ensure homogeneous study groups. Patients with malignancy, inflammatory rheumatic disease (rheumatoid arthritis, systemic lupus erythematosus, ankylosing spondylitis, etc.) and those with a known history of systemic disease (hypertension, diabetes mellitus, neurological or psychiatric disease, etc.) were excluded. The control group consisted of female respondents with no systemic, genetic, hormonal or psychiatric diseases, including FMS and regional pain syndrome. The study protocol was approved by the Cumhuriyet University Clinical Research Ethics Committee (Approval \#: 201702/25, dated: 28.02.2017). A written informed consent was obtained from each patient. The study was conducted in accordance with the principles of the Declaration of Helsinki.

Clinical symptoms (sleep disturbances, morning fatigue, paresthesia, and feeling of swelling in soft tissues) and family history of FMS were inquired and recorded. The visual analog scale (VAS) and Fibromyalgia Impact Questionnaire (FIQ) were administered 
to the patients with FMS, and their scores were recorded. Venous blood samples of all participants were collected into sterile citrate tubes, and genomic deoxyribonucleic acid (DNA) was isolated from the collected blood samples. Following DNA isolation, the blood samples in the citrate tubes were stored at $-20^{\circ} \mathrm{C}$.

A 20-item FIQ was used to assess the patients' physical function, occupational status, depression, anxiety, sleep, pain, rigidity, fatigue and healthiness as a means of evaluating the functional status of the patients and the progression and outcomes of the disease. ${ }^{25}$ The validity and reliability of the study were demonstrated in our country by Sarmer et al. ${ }^{26}$

The VAS was used to examine the pain levels of the patients. On a $10-\mathrm{cm}$ scale on which 0 indicates no pain and 10 indicates the most severe pain, the patients were asked to mark the point that best corresponds to the level of pain they experience.

The blood samples of patients with FMS and of the control subjects were collected into 4-mL sodium citrate tubes. Genomic DNA was isolated via the DNA isolation method using a high salt concentration. ${ }^{27}$

A Nanodrop Spectrophotometer (ND-1000 NanoDrop Technologies Inc., Wilmington, DE, USA) was used to quantify and determine the quality of the DNA. The concentration of DNA samples was expressed as $\mathrm{ng} / \mu \mathrm{L}$. After the quantification of the DNA samples via the Nanodrop spectrophotometer, the best results were observed at a concentration of $5 \mathrm{ng} / \mu \mathrm{L}$ during optimization studies in DNA samples for ADRB2 (rs1042717), and the concentration was set to this value.

The detection of the Rs1042717 SNP was performed by real-time polymerase chain reaction using FAM-VIC-labeled primers. The wild-type FAM probe (Guanine/Guanine [GG]) generates green fluorescence and the mutant VIC probe (Adenine/Adenine [AA]) generates yellow fluorescence, while heterozygous (AG) samples generate both yellow and green fluorescence. We also tested for contamination of the disposed materials or experimental environment for control number 4 (Figure 1).

CCTGTGCTGATCTGGTCATGGGCCT[A/G] GCAGTGGTGCCCT T TGGGGCCGCCC
Chromosome: 5q32, Gene: ADRB2, Region: Intron, Base length: 1242 bp

\section{Statistical analysis}

Analyses were performed using the IBM SPSS Statistics 22.0 (IBM Corp., Armonk, NY, USA) software package. The normal distribution of the data was analyzed using KolmogorovSmirnov tests. Student's t test was applied when the parametric test assumptions were met. A Mann-Whitney $U$ test was used when the parametric test assumptions could not be met, and a Chi-square test was used to evaluate the categorical data. The data were expressed in tables in number, percentage and mean \pm standard deviation forms, and a $p$ value of $<0.05$ was considered statistically significant. The Chi square test was used to calculate Hardy-Weinberg equilibrium. The power of the study according to minor allele frequency ${ }^{28}$ was found to be $p=0.8109$ when the $p^{1}=0.98$, $\mathrm{p}^{2}=0.91, \alpha=0.05$, and $\beta=0.20$.

\section{RESULTS}

Clinical symptoms of FMS patients are shown in Table 1. A comparison of the ADRB2 gene polymorphism (rs1042717) between patients with FMS and the control subjects showed that the

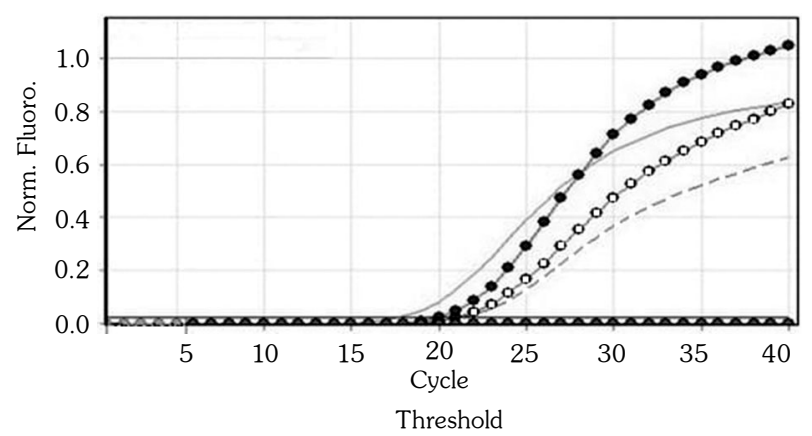

\begin{tabular}{|l|c|l|l|l|l|}
\hline No & Colour & Name & Genotype & $\begin{array}{l}\text { Cycling } \\
\text { A. Green }\end{array}$ & $\begin{array}{l}\text { Cycling } \\
\text { A. Yellow }\end{array}$ \\
\hline 1 & $\bigcirc$ & FMS 1 & Heterozygous & Reaction & Reaction \\
\hline 2 & $\bigcirc$ & FMS 2 & Mutant & No reaction & Reaction \\
\hline 3 & - & FMS 3 & Wild type & Reaction & No reaction \\
\hline 4 & $\triangle$ & Control & & No reaction & No reaction \\
\hline
\end{tabular}

Figure 1. Identification of beta-2 adrenergic receptor polymorphism (rs1042717) genotypes FMS: Fibromyalgia syndrome. 
Table 1. Clinical symptoms of patients with fibromyalgia syndrome $(n=170)$

\begin{tabular}{lcc}
\hline & $\mathrm{n}$ & $\%$ \\
\hline Sleep disturbances & 138 & 81.2 \\
Fatigue & 163 & 95.9 \\
Paresthesia & 127 & 74.7 \\
Swelling of soft tissues & 130 & 76.5 \\
Family history of fibromyalgia & 80 & 47.1 \\
\hline
\end{tabular}

groups were similar in terms of rs1042717 gene polymorphism and genotype ( $>0.05$ ) (Table 2). There was no significant difference in terms of genotype when the genotypes (GG, AG, AA) of the ADRB2 gene polymorphism (rs1042717) in patients with FMS were compared in terms of clinical symptoms and VAS and FIQ scores (p>0.05) (Table 3).

\section{DISCUSSION}

The present study has demonstrated that ADRB2 gene polymorphisms (rs1042717) and the different genotypes of the ADRB2 gene polymorphism in patients with FMS are no different from those of the healthy control subjects. Furthermore, the clinical symptoms of FMS and VAS and FIQ scores were found to be similar in patients with FMS with different genotypes of the ADRB2 gene polymorphism (rs1042717). To the best of our knowledge, this is the first study to report these findings in Turkish patients with FMS.

Fibromyalgia syndrome is a significant health problem that restricts the daily life activities of its sufferers. There are various clinical symptoms in patients with FMS, although chronic pain is one of the most common. There is evidence suggesting that genetic polymorphisms, together with psychological and physiological components, contribute to the development of chronic pain..$^{29,30}$ Pain is affected by the ARs of the autonomic nervous system. Increasing levels of catecholamines result in the occurrence of persistent pain through stimulation of the ADRBs in the peripheral and central nervous system. For this reason, $\beta$-adrenergic antagonist propranolol has been suggested for the treatment

\begin{tabular}{|c|c|c|c|c|c|}
\hline \multirow[b]{2}{*}{ Rs1042717 } & \multicolumn{2}{|c|}{ Fibromyalgia group ( $\mathrm{n}=170$ ) } & \multicolumn{2}{|c|}{ Control group $(n=170)$} & \multirow[b]{2}{*}{$p$} \\
\hline & $\mathrm{n}$ & $\%$ & $\mathrm{n}$ & $\%$ & \\
\hline Guanine/Guanine & 25 & 14.7 & 15 & 8.8 & \multirow{3}{*}{$\begin{array}{c}0.174 \\
\chi^{2}=3.49\end{array}$} \\
\hline Adenine/Guanine & 123 & 72.4 & 126 & 74.1 & \\
\hline Adenine/Adenine & 22 & 12.9 & 29 & 17.1 & \\
\hline
\end{tabular}

Table 3. Comparison of clinical symptoms, Fibromyalgia Impact Questionnaire and visual analog scale scores among different genotypes of beta-2 adrenergic receptor gene polymorphism (rs1042717) in patients with fibromyalgia syndrome

\begin{tabular}{|c|c|c|c|c|c|c|c|c|c|c|}
\hline & \multicolumn{3}{|c|}{$\mathrm{AA}(\mathrm{n}=25)$} & \multicolumn{3}{|c|}{ AG $(n=123)$} & \multicolumn{3}{|c|}{ GG $(n=22)$} & \multirow[b]{2}{*}{$p$} \\
\hline & $\mathrm{n}$ & $\%$ & Mean \pm SD & $\mathrm{n}$ & $\%$ & Mean \pm SD & $\mathrm{n}$ & $\%$ & Mean \pm SD & \\
\hline Sleep disturbances & 19 & 76 & & 101 & 82 & & 18 & 82 & & $0.976^{*}$ \\
\hline Fatigue & 22 & 88 & & 123 & 100 & & 22 & 100 & & $0.522^{*}$ \\
\hline Paresthesia & 18 & 72 & & 93 & 76 & & 16 & 73 & & $0.902^{*}$ \\
\hline Swelling of soft tissues & 17 & 68 & & 94 & 76.4 & & 19 & 86 & & $0.498^{*}$ \\
\hline FIQ & & & $63.7 \pm 12.2$ & & & $62.3 \pm 11.9$ & & & $59.3 \pm 15.9$ & $0.473^{* *}$ \\
\hline Visual analog scale & & & $6.9 \pm 1.2$ & & & $6.6 \pm 1.4$ & & & $6.6 \pm 1.7$ & $0.776^{* * * *}$ \\
\hline
\end{tabular}

AA: Adenine/Adenine; AG: Adenine/Guanine; GG: Guanine/Guanine; SD: Standard deviation; FIQ: Fibromyalgia Impact Questionnaire; * Chi-square test was used; "* Mann-Whitney U test was used; *** T-test was used. 
of migraine. ${ }^{31}$ In another study, Wood et al. ${ }^{32}$ have shown that pindolol may have beneficial effects on cardinal symptoms, including sleep and pain, in the treatment of FMS. ADRBs are membrane-integrated proteins that mediate the effects of catecholamines on the cell surface. ADRB2 is found in the central nervous system and peripheral tissues, and is responsible for pain signals. ${ }^{33}$ In a previous study by Khasar et al., ${ }^{34}$ the activation of peripheral ADRB2 has been shown to cause increased pain sensitivity and hyperalgesia. In another study, the ADRB2 gene polymorphism was suggested to play a role in chronic musculoskeletal pain. ${ }^{19}$ VargasAlarcón et al. ${ }^{23}$ have evaluated different SNPs of alpha-1 (rs574584, rs1383914, rs1048101 and rs573542), beta-2 (rs1042713 and rs1042714) and beta-3 (rs4994) ARs in patients with FMS of Spanish and Mexican origin, and shown that the ADRB2 AC haplotype is more common in patients with FMS that are of Spanish and Mexican origin than in healthy control subjects. Furthermore, Vargas-Alarcón et al. ${ }^{23}$ have found that alpha-1 AR SNP (rs1383914) is found more frequently in Spanish patients with FMS than in healthy control subjects. In another study evaluating the relationship between FMS and the ADRB2 polymorphism (rs1042713 and rs1042714), Xiao et al. ${ }^{22}$ have reported no significant difference between patients with FMS and healthy control subjects. The findings of the present study are similar to those reported by Xiao et al., ${ }^{22}$ but different to those reported by Vargas-Alarcón et al. ${ }^{23}$ The present study has also found no significant difference in the ADRB2 gene polymorphism (rs1042717) and haplotypes between patients with FMS and healthy control subjects. The difference between the present findings and those reported by Vargas-Alarcón et al. ${ }^{23}$ may be attributed to be the differences in the ethnic origin of the studied patients with FMS and the number of studied SNPs being different in the two studies.

Aside from the risk of developing FMS, AR gene polymorphisms have also been associated with different clinical characteristics of FMS. ${ }^{22,23}$ In their study, Vargas-Alarcón et al. ${ }^{23}$ have shown that morning stiffness and fatigue are more frequent and FIQ scores are higher in Mexican patients with FMS carrying the GG genotype of the 1-AR polymorphism (rs574584) than in other patients with FMS. In their study, Xiao et al. $^{22}$ have identified an association between the ADRB2 gene polymorphism in patients with FMS and sleep disturbances. The present study has detected no significant difference in the clinical symptoms or FMS, FIQ or VAS scores of patients with FMS carrying the ADBR2 gene polymorphism (rs1042717) and/or different genotypes of the ADRB2 gene polymorphism. The results of the present study differ from those reported in previous studies, which may be attributed to differences in the number of studied SNPs and the ethnic origin of the studied patients with FMS.

The limitations of the present study include the absence of male patients with FMS and healthy males as a separate group in addition to the relatively small sample size.

In conclusion, the ADRB2 (rs1042717) gene polymorphisms and genotypes do not differ between patients with FMS and healthy individuals. Furthermore, the ADRB2 (rs1042717) gene polymorphism in FMS has no effect on the symptoms of FMS. In addition, this study did not find any association between ADRB2 polymorphisms and FIQ or VAS score. However, the evaluation of only one SNP is not sufficient to determine the role of the ADRB2 polymorphism in the etiopathogenesis of FMS, and so further comprehensive clinical studies with larger sample size are required evaluating different SNPs.

\section{Declaration of conflicting interests}

The authors declared no conflicts of interest with respect to the authorship and/or publication of this article.

\section{Funding}

This study was supported by the Scientific Research Project Fund of Cumhuriyet University (project No. $\mathrm{T}-733)$.

\section{REFERENCES}

1. Metyas S, Rezk T, Arkfeld D, Leptich T. Autoinflammation and Immunomodulation in Inflammatory Fibromyalgia Syndrome- A Review. Curr Rheumatol Rev 2017;13:98-102.

2. Dadabhoy D, Clauw DJ. Therapy Insight: fibromyalgia-a different type of pain needing a different type of treatment. Nat Clin Pract Rheumatol 2006;2:364-72. 
3. Albrecht PJ, Rice FL. Fibromyalgia syndrome pathology and environmental influences on afflictions with medically unexplained symptoms. Rev Environ Health 2016;31:281-94.

4. Martínez-Lavín M, Hermosillo AG. Autonomic nervous system dysfunction may explain the multisystem features of fibromyalgia. Semin Arthritis Rheum 2000;29:197-9.

5. Diatchenko L, Slade GD, Nackley AG, Bhalang K, Sigurdsson A, Belfer I, et al. Genetic basis for individual variations in pain perception and the development of a chronic pain condition. Hum Mol Genet 2005;14:135-43.

6. Bellato E, Marini E, Castoldi F, Barbasetti N, Mattei L, Bonasia DE, et al. Fibromyalgia syndrome: etiology, pathogenesis, diagnosis, and treatment. Pain Res Treat 2012;2012:426130.

7. Martínez-Martínez LA, Mora T, Vargas A, FuentesIniestra M, Martínez-Lavín M. Sympathetic nervous system dysfunction in fibromyalgia, chronic fatigue syndrome, irritable bowel syndrome, and interstitial cystitis: a review of case-control studies. J Clin Rheumatol 2014;20:146-50.

8. Buskila D. Developments in the scientific and clinical understanding of fibromyalgia. Arthritis Res Ther 2009;11:242.

9. Ablin J, Neumann L, Buskila D. Pathogenesis of fibromyalgia - a review. Joint Bone Spine 2008;75:273-9.

10. Giacomelli C, Sernissi F, Sarzi-Puttini P, Di Franco M, Atzeni F, Bazzichi L. Fibromyalgia: a critical digest of the recent literature. Clin Exp Rheumatol 2013;31:S153-7.

11. Gürsoy S, Erdal E, Herken H, Madenci E, Alaşehirli B, Erdal N. Significance of catechol-O-methyltransferase gene polymorphism in fibromyalgia syndrome. Rheumatol Int 2003;23:104-7.

12. Josep García-Fructuoso F, Ignacio Lao-Villadóniga J, Beyer K, Santos C. Relationship between COMT gene genotypes and severity of fibromyalgia. Reumatol Clin 2006;2:168-72.

13. Vargas-Alarcón G, Fragoso JM, Cruz-Robles D, Vargas A, Vargas A, Lao-Villadóniga JI, et al. Catechol-Omethyltransferase gene haplotypes in Mexican and Spanish patients with fibromyalgia. Arthritis Res Ther 2007;9:R110.

14. Bozkaya ÖG. Klinisyenler için mutasyon ve polimorfizm. Turkiye Klinikleri J Pediatr 2009;18:47-53.

15. Sherry ST, Ward MH, Kholodov M, Baker J, Phan L, Smigielski EM, et al. dbSNP: the NCBI database of genetic variation. Nucleic Acids Res 2001;29:308-11.

16. Covolo L, Gelatti U, Metra M, Nodari S, Piccichè A, Pezzali N, et al. Role of beta1- and beta2-adrenoceptor polymorphisms in heart failure: a case-control study. Eur Heart J 2004;25:1534-41.

17. Mohamed-Hussein AAR, Sayed SS, Eldien HMS, Assar AM, Yehia FE. Beta 2 Adrenergic Receptor Genetic Polymorphisms in Bronchial Asthma: Relationship to Disease Risk, Severity, and Treatment
Response. Lung 2018;196:673-80.

18. Feng $\mathrm{S}$, Li N, Xu S, Wang H, Yu W, Lu Y, et al. Association of ADRB1 gene polymorphisms with pain sensitivity in a Chinese population. Int $\mathrm{J}$ Clin Exp Med 2015;8:11514-8.

19. Hocking LJ, Smith BH, Jones GT, Reid DM, Strachan DP, Macfarlane GJ. Genetic variation in the beta2-adrenergic receptor but not catecholamine-Omethyltransferase predisposes to chronic pain: results from the 1958 British Birth Cohort Study. Pain 2010;149:143-51.

20. Brodde OE. Beta-1 and beta-2 adrenoceptor polymorphisms: functional importance, impact on cardiovascular diseases and drug responses. Pharmacol Ther 2008;117:1-29.

21. Diatchenko L, Anderson AD, Slade GD, Fillingim RB, Shabalina SA, Higgins TJ, et al. Three major haplotypes of the beta2 adrenergic receptor define psychological profile, blood pressure, and the risk for development of a common musculoskeletal pain disorder. Am J Med Genet B Neuropsychiatr Genet 2006;141B:449-62.

22. Xiao Y, He W, Russell IJ. Genetic polymorphisms of the beta2-adrenergic receptor relate to guanosine proteincoupled stimulator receptor dysfunction in fibromyalgia syndrome. J Rheumatol 2011;38:1095-103.

23. Vargas-Alarcón G, Fragoso JM, Cruz-Robles D, Vargas A, Martinez A, Lao-Villadóniga JI, et al. Association of adrenergic receptor gene polymorphisms with different fibromyalgia syndrome domains. Arthritis Rheum 2009;60:2169-73.

24. Wolfe F, Clauw DJ, Fitzcharles MA, Goldenberg DL, Katz RS, Mease P, et al. The American College of Rheumatology preliminary diagnostic criteria for fibromyalgia and measurement of symptom severity. Arthritis Care Res (Hoboken) 2010;62:600-10.

25. Burckhardt CS, Clark SR, Bennett RM. The fibromyalgia impact questionnaire: development and validation. J Rheumatol 1991;18:728-33.

26. Sarmer S, Ergin S, Yavuzer G. The validity and reliability of the Turkish version of the Fibromyalgia Impact Questionnaire. Rheumatol Int 2000;20:9-12.

27. Miller SA, Dykes DD, Polesky HF. A simple salting out procedure for extracting DNA from human nucleated cells. Nucleic Acids Res 1988;16:1215.

28. Relethford JH. Hardy-Weinberg equilibrium. In: Cartmill M, Brown K, Relethford JH, editors. Human Population Genetics. 1st ed. New Jersey: John Wiley \& Sons; 2012. p. 23-48.

29. Higgins TJ. Molecular Characterization of $\beta 2$ Adrenergic Receptor Haplotypes. Thesis (Neurobiyology) University of North Caroline at Chapel Hill, 2008;15-8.

30. Diatchenko L, Nackley AG, Slade GD, Fillingim RB, Maixner W. Idiopathic pain disorders--pathways of vulnerability. Pain 2006;123:226-30.

31. Diamond S, Solomon GD, Freitag FG, Mehta ND. Long-acting propranolol in the prophylaxis of migraine. Headache 1987;27:70-2. 
32. Wood PB, Kablinger AS, Caldito GS. Open trial of pindolol in the treatment of fibromyalgia. Ann Pharmacother 2005;39:1812-6.

33. Aley KO, Martin A, McMahon T, Mok J, Levine JD, Messing RO. Nociceptor sensitization by extracellular signal-regulated kinases. J Neurosci
2001;21:6933-9.

34. Khasar SG, McCarter G, Levine JD. Epinephrine produces a beta-adrenergic receptor-mediated mechanical hyperalgesia and in vitro sensitization of rat nociceptors. J Neurophysiol 1999;81:110412. 